\title{
O DEBATE DE GÊNERO COMO PRÁTICA PEDAGÓGICA: UMA ANÁLISE DAS PRODUÇÕES ACADÊMICAS SOBRE IGUALDADE DE GÊNERO NAS ESCOLAS ENTRE 2003 A 2014
}

\author{
GENDER DEBATE AS A PEDAGOGICAL PRACTICE: AN ANALYSIS OF ACADEMIC \\ PRODUCTIONS ON GENDER EQUALITY IN SCHOOLS BETWEEN 2003 AND 2014
}

Anna Karina Gonçalves Xavier ${ }^{1}$, Arthur Silva de Andrade ${ }^{2}$, Lúcia Talita Santos de Lima $^{3}$, Renato Silva Maciel dos Santos ${ }^{4}$, Beatriz Coelho Ferreira ${ }^{5}$

${ }^{1}$ Centro Universitário Estácio do Recife, Departamento de Psicologia., Brasil, e-mail: akpsicologia@hotmail.com, ORCID: https://orcid.org/0000-0002-1127-3915

2Centro Universitário Estácio do Recife, Departamento de Psicologia., Brasil, e-mail: arthurpsique@gmail.com, ORCID: https://orcid.org/0000-0002-9111-1771

${ }^{3}$ Centro Universitário Estácio do Recife, Departamento de Psicologia., Brasil, e-mail: talitasantosdlima@gmail.com, ORCID: https://orcid.org/0000-0003-1705-8703

4 Centro Universitário Estácio do Recife, Departamento de Psicologia., Brasil, e-mail renatopsimaciel@gmail.com, ORCID: https://orcid.org/0000-0003-2418-8362

5 Centro Universitário Estácio do Recife, Departamento de Psicologia., Brasil, e-mail: beatrizcoelhoferreira@gmail.com, ORCID: https://orcid.org/0000-0001-9554-2344

\author{
ARTICLE INFO \\ Article history: \\ Received 2020-06-02 \\ Accepted 2020-11-30 \\ Available online 2020-11-30
}

Palavras-chave: gênero, feminismo, educação, ensino fundamental.

Keywords: gender, feminism, education, elementary education.

RESUMO. A proposta do presente trabalho é apresentar e discutir um mapeamento de teses e dissertações produzidas durante o período de 2003 a 2014 a respeito das práticas docente no ensino fundamental sobre igualdade de gênero, um dos temas transversais incluído nos Parâmetros Curriculares Nacionais na década de 90. O objetivo foi através das produções acadêmicas identificar o que os(as) professores(as) estão fazendo a respeito dessa temática em sala de aula. O corpus da pesquisa consiste em um total de 8 publicações referentes ao trabalho de gênero, educação e ensino, sendo 2 teses e 6 dissertações. Após a análise do corpus, conclui-se que há um limitado número de produções acadêmicas, durante o período estudado sobre as práticas docentes referente a igualdade de gênero no ensino fundamental, além de uma formação sem que se trabalhe temáticas como gênero, orientação religiosa por parte do corpo docente, receio por parte dos(as) professores(as) de serem acusados de impulsionar a sexualidade nas meninas e a homossexualidade nos meninos.

ABSTRACT. The purpose of this paper is to present and discuss a mapping of theses and dissertations produced during the period from 2003 to 2014 regarding teaching practices in fundamental education on gender equality, one of the transversal themes included in the National Curricular Parameters in the 90s. The objective was through academic productions to identify what teachers are doing about this theme in the classroom. The research corpus consists of a total of 8 publications related to gender work, education and teaching, with 2 theses and 6 dissertations. After analyzing the corpus, it is concluded that there is a limited number of academic productions, during the period studied on teaching practices regarding gender equality in elementary school, in addition to training without working on themes such as gender, religious orientation by part of the faculty, teachers' fear of being accused of boosting sexuality in girls and homosexuality in boys. 


\section{Introdução}

Recentemente houve no Brasil uma campanha contra as chamadas "ideologias de gênero", em função dos projetos populistas de direita (PATERNOTTE, KUHAR, 2018). A introdução de temas transversais como raça e gênero nos Parâmetros Curriculares Nacionais (PCN's) foi fruto de um longo movimento de luta para que a ideia de uma sociedade brasileira sem preconceito, discriminação e desigualdade se materializasse pela via da educação, no qual brasileirinhos e brasileirinhas aprendessem a respeitar uns aos outros independente das cor da pele ou gênero, dando relevância aos aspectos da dignidade da pessoa, igualdade de direitos, participação ativa em sociedade e a corresponsabilidade pela vida social (VIANNA e UNBEHAUM, 2004).

Esse movimento teve como início o momento histórico de reintegração das instituições democráticas anuladas pelo regime militar, a denominada redemocratização brasileira durante as décadas de 70 e 80 . Nestas duas décadas aconteceu um processo de grandes transformações políticas no território; na década de 70 , diversas mulheres foram as ruas reivindicando pautas como a anistia, contra a carestia e violência. Já na década de 80 , podemos observar a presença da mulher em assembleia legislativa, destacando-se aqui o estado de São Paulo (SP), fruto das eleições diretas ocorrida nesta década. Em 1988, com a promulgação da Constituição, dá-se enfim o início da invisibilidade da mulher, através do estabelecimento da igualdade entre homens e mulheres (BRABO, 2008).

$\mathrm{Na}$ década de 90, a elaboração dos PCN'S, que são diretrizes elaboradas pelo Governo Federal no qual respaldam a educação brasileira, abordaram as questões de gênero em todos os níveis de ensino. E o movimento feminista teve ação direta sobre essa conquista, uma das consequências da luta iniciada no período de redemocratização do país, nesse sentido, os PCN'S objetivam:

[...] o combate a relações autoritárias, questionar a rigidez dos padrões de conduta estabelecidos para homens e mulheres e apontar para sua transformação, incentivando, nas relações escolares, a diversidade de comportamento de homens e mulheres, a relatividade das concepções tradicionalmente associadas ao masculino e feminino, o respeito pelo outro sexo e pelas variadas expressões do feminino e do masculino. (BRASIL, 1997, p.144).

Porém, mesmo após os longos debates na década de 80 sobre gênero, essas questões perderam-se, temas transversais incluídos nos PCN'S foram recebidos com resistência na década citada e ainda nos dias atuais. Esperava-se que, diante de toda a luta, conquistas, realizações, vivências e valores de igualdade meninas e meninos passariam a se ver como cidadãos de direitos e compreenderiam o seu papel de cidadão e cidadã, questão essencial para a transição e consolidação da democracia.

No âmbito da Política de Estado, houve outro grande ganho para o movimento feminista, foi a criação em 2003 da "Secretaria Especial de Políticas para Mulheres", objetivando desenvolver ações conjuntas com todos ministérios e secretarias especiais e a 
qual contribuiu acerca da educação para a igualdade de gênero. Esse órgão ministerial criado no primeiro dia do governo do presidente Luiz Inácio Lula da Silva buscou o estabelecimento de políticas públicas para a melhoria da vida de todas as mulheres do Brasil (BRABO, 2008). Apesar do reduzido avanço, frente as conquistas que se almeja no cenário político, não se pode negar, que a história de luta das mulheres revela êxitos.

A pesquisa objetivou analisar as produções acadêmicas, no período de 2003-2014, sobre igualdade de gênero nas escolas de ensino fundamental no Brasil especialmente teses e dissertações, no banco de teses e dissertações da CAPES. A decisão por este período possui como motivação o fato de ter sido o momento brasileiro em que as pautas feministas e de outros movimentos minoritários foram mais atendidas pelo Governo Federal, deveras em função do modelo de gestão que esteve presente no país.

\section{DIÁLOGOS PERTINENTES}

Segundo Gayle Rubin (1993), as bibliografias sobre mulheres antifeministas e feministas, dão-se por uma vasta reflexão sobre a gênese, natureza da subordinação e opressão social que é imposta sobre as mulheres, uma avaliação sobre a coação de mulheres pode ser usada como alicerce para uma definição do que precisa ser modificado para construção de uma sociedade sem hierarquia fundada em gênero.

Para Joan Scott (1990), as desigualdades de poder são estruturadas por no mínimo três eixos sendo eles: classe, raça e gênero. A autora sugere uma analogia entre os três termos, porém, não existe um estatuto equivalente. Segundo a autora, classe é fundada na teoria marxista sobre uma determinação econômica e modificação histórica, já raça e gênero não possuem associação semelhante. Sabe-se que não existe uma uniformidade entre os que usam o conceito de classe, portanto ao usar o termo é provocado uma ideia de causalidade econômica e a visão de que a história avançou dialeticamente. No entanto não existe compreensão ou acordo para raça e gênero. Ao se falar de gênero existe uma vasta gama de posições teóricas e simples referências descritivas na relação entre os sexos.

O termo gênero torna-se um meio de apontar construções culturais, uma elaboração completamente social de entendimentos sobre os papéis impostos para homens e mulheres. Sendo, uma forma de apontar a gênese inteiramente social das identidades subjetivas de mulheres e homens. A partir dessa definição, gênero se enquadra como uma condição social exigida sobre um corpo sexuado. Após à manifestação de estudos sobre sexualidade e sexo, gênero, virou um termo de utilidade, pois torna-se uma forma de diferenciar a prática sexual dos papéis impostos às mulheres e homens (SCOTT, 1990).

Ainda para Scott (1990), o emprego do termo gênero destaca um conjunto de ligações que podem abranger sexo, porém não é diretamente determinado pelo sexo, e também, não determina a sexualidade. A autora ainda afirma: 
Os/as historiadores/as feministas têm empregado uma variedade de abordagens na análise do gênero, mas essas podem ser resumidas a três posições teóricas. A primeira, uma tentativa inteiramente feminista, empenha-se em explicar as origens do patriarcado. A segunda se situa no interior de uma tradição marxista e busca um compromisso com as críticas feministas. A terceira, fundamentalmente dividida entre o pós-estruturalismo francês e as teorias angloamericanas de relação do objeto (object-relation theories), se inspira nessas diferentes escolas de psicanálise para explicar a produção e a reprodução da identidade de gênero do sujeito (SCOTT, 1990, p.77).

As teorias usadas pelo patriarcado concentram seu foco à subordinação das mulheres e justifica tal ideia na "necessidade" masculina de ter domínio sobre as mulheres. A autora afirma que as primícias da libertação das mulheres estão na compreensão correta do processo de reprodução. Em uma avaliação mais materialista essa libertação seria possível através de transformações nas tecnologias da reprodução, que possibilitariam no futuro exterminar a necessidade de corpos femininos como condutores da reprodução da espécie (O'BRIEN, 1981).

McKinnon (1982), afirma que a objetificação sexual é a elaboração inicial da submissão das mulheres. Mesmo ainda, que as relações sexuais sejam estabelecidas como sociais, não existe, além da desigualdade própria em relação a si mesma, que defina porque o sistema de poder funciona dessa forma. O início dessa desigualdade existente entre os sexos, no fim das contas, está, nas relações desiguais entre os mesmos.

Scott (1990), afirma que, se a dominação e agressão masculina inatas servem para surgimento da opressão das mulheres, os movimentos feministas poderiam reivindicar 0 aniquilamento do sexo agressor ou uma forma de mudar o seu caráter.

Como foi dito anteriormente, no decorrer da nossa sociedade as mulheres foram postas em dúvidas, ditas como incapazes e tantos outros adjetivos pejorativos que eram impostos com intenção de inferiorizar, mas no desenvolver de uma sociedade moderna as mulheres tomaram consciência da submissão que vivenciavam, aos poucos foram lutando e avançando em lutas políticas e na conquista de direitos para mudar essa realidade opressiva (GREGORI, 2017).

O movimento feminista surgiu através de lutas coletivas das mulheres contra as condições de aversão e inferiorização, contra o sexismo e para mudança de práticas cotidianas de subordinação. O feminismo é uma grande forma de estratégia para quebra da desigualdade e de uma estrutura patriarcal (BANDEIRA e MELO, 2010).

Através de diferentes formas de atuação, a luta feminista é pela cidadania, pela liberdade e vida de diversas mulheres. Tendo como pautas:

Direito a existir com dignidade, direito de propriedade, direito à educação e ao trabalho, direito de votar e ser eleita, direito a participar de espaços de poder e decisão, direito a seu próprio corpo, direito a viver livre de violências, direito de viver em igualdade de condições com os homens (BANDEIRA e MELO, 2010, p. 9).

Sendo assim, o feminismo tem como base um processo permanente de ações coletivas que são pautadas na emancipação política e na conquista de direitos que espelham 
o empoderamento das mulheres. Como também faz críticas e denúncias sobre as injustiças da sociedade patriarcal, sendo um movimento plural que afronta o sistema de dominação, tendo como intuito uma transformação social (SILVA e CAMURÇA, 2010).

Com isso, pode-se dizer que o feminismo tem um caráter múltiplo, que agrega diferentes vertentes. Alguns estudos sobre a história do movimento feminista, usam o termo "onda" para indicar algum momento histórico que teve movimentos e organizações feministas reivindicando a mesma pauta. No Brasil e no mundo ocidental, a primeira onda diz respeito ao movimento sufragista; a segunda onda, teve início na década de 1960-1970 e se caracteriza por uma crítica radical, teórica e prática sobre o modelo de mulher de família vigente. Já a terceira onda, que surgiu nos anos 1990, engloba mulheres negras, lésbicas, mulheres do terceiro mundo, transgênero, dentre outras (RABAY e CARVALHO, 2011).

Enquanto organização de manifesto político, o feminismo surgiu em conjunto a uma mobilização da Revolução Francesa, onde se concebeu como uma grande revolução burguesa (COSTA e SARDENBERG, 2008). O feminismo, enquanto movimento social e moderno foi iniciado entorno da Revolução Francesa e Americana, teve por primeiras demandas lutas por direitos sociais e políticos (COSTA, 2005).

Após impulsionar mulheres da Europa e dos Estados Unidos, o movimento também se estendeu em países da América Latina, como Brasil, Chile, Argentina, México, Peru e Costa Rica. As manifestações eram expostas sobretudo na imprensa, com intuito de atingir cada vez mais pessoas (COSTA, 2005).

Formando vestígios de revolução, foi espalhado mundialmente. As pautas feministas crescem no Brasil na segunda metade do século XIX, onde diversas mulheres fizeram parte de revoltas que interviram na construção do país (BANDEIRA e MELO, 2010). Pode-se dizer que:

O feminismo no Brasil vem assumindo várias formas de luta, diversas bandeiras e diferentes facetas. Já foi sufragista, anarquista, socialista, comunista, burguês e reformista. Já lutou no parlamento, nas ruas e nas casas para conquistar e garantir o acesso da mulher à educação formal. E vem lutando pela igualdade de salários e condições dignas de trabalho, pela valorização do trabalho doméstico, pelo direito inalienável de todas ao controle sobre o próprio corpo e gozo de nossa sexualidade, enfim, pela construção de uma sociedade mais justa e igualitária, onde a mulher possa realizar-se plenamente enquanto ser humano e cidadã (COSTA e SARDENBERG, 2008, p. 32).

Ainda existindo tantas restrições para às mulheres dessa época, as mesmas lutaram na causa abolicionista, pelo fim da escravidão. Já por volta de 1890 a luta nacional foi pelo direito ao voto. Esse período foi chamado de primeira onda do movimento feminista (BANDEIRA e MELO, 2010). Em 1920, o sufragismo que foi o movimento de luta pelo voto das mulheres, se formou como uma expressão política organizada (RABAY e CARVALHO, 2011). Segundo Ana Alice Costa e Cecília Sardenberg (2005), por volta da metade do século $X X$, a luta sufragista cresce e abarca diversos países latino-americanos, sendo conduzido por 
mulheres de classe alta e média, onde, por volta de uma ação direta com os aparelhos legislativos, ganharam a luta pelo direito ao voto.

De acordo com Lourdes Bandeira e Hildete Melo (2010), o primeiro estado brasileiro onde foi permitido que mulheres votassem nas eleições foi o Rio Grande do Norte, em 1927, mas a Comissão de Poderes do Senado desconsiderou todos os votas das eleitoras. A luta das sufragistas brasileiras seguiu até 1932, onde a reivindicação foi concedida pelo governo implantado pela "Revolução de 1930" (COSTA e SARDENBERG, 2008). Com isso as mulheres tiveram uma participação ativa na política, não apenas com o voto, mas também como candidatas para cargos como prefeitas, deputadas estaduais, deputadas federais e até senadoras (BANDEIRA e MELO, 2010).

O movimento feminista no Brasil, nos Estados Unidos, Europa e países latinoamericanos, entraram em desarticulação, mas não só o feminismo passou por problemas políticos, como toda a sociedade do país, pois:

A democracia brasileira dos anos 1930 seria efêmera, já que, em 10 de novembro de 1937, um golpe militar-político restringe as liberdades democráticas, fecha o Congresso Nacional e extingue os partidos políticos. Este episódio ficou conhecido na história do Brasil como Estado Novo. Os Poderes Legislativos nacional, estadual e municipal seriam extintos por quase 10 anos, até a restauração democrática em outubro de 1945 (BANDEIRA e MELO, 2010, p. 20).

Com o golpe militar no Brasil, em 1964, os movimentos de mulheres, como o feminismo burguês, movimentos populares e de esquerda, foram calados, suprimidos e massacrados. Vale ressaltar que os movimentos de mulheres burguesas e de classe média, que eram organizados por conservadores, tiveram um desempenho importante no apoio aos golpes militares e também na resistência aos governos militares. As mulheres foram eleitas para Câmara Federal, nas eleições de 1965, onde, representavam seus maridos, irmãos e demais parentes cassados pelos Atos Institucionais do Regime Militar (COSTA, 2005; COSTA e SARDENBERG, 2008; BANDEIRA e MELO, 2010).

Costa (2005), afirma que esse primeiro período do movimento feminista, pode ser descrito como conservador, pois reforçava os papeis e estereótipos de gênero. A repressão ocasionada pela ditadura militar serviu para uma enorme mudança nos movimentos sociais, e após isso encerra-se o ciclo da primeira onda do feminismo.

Após uma pausa obrigatória pelos anos da ditadura militar, o movimento feminista volta a se programar, em meados da década de setenta (COSTA e SARDENBERG, 2008). Nesse cenário, o feminismo se articula em prol de um movimento que questiona os parâmetros conceituais do político, para com isso quebrar as limitações desse conceito, que até então era identificado como âmbito apenas da esfera pública e das relações sociais (COSTA, 2005).

O feminismo deu abertura para o rompimento da dicotomia público-privado, pensamento esse que é o suporte do pensamento liberal sobre política e poder político, "para o pensamento liberal, o conceito de público diz respeito ao Estado e às suas instituições, à 
economia. Já o privado se relaciona com a vida doméstica, familiar e sexual, identificado com o pessoal, alheio à política" (COSTA, 2005, p. 10).

Com o alargamento do pensamento feminista e uma crítica a condição do ser feminino, as mulheres foram as ruas para gritar "Nosso Corpo nos Pertence e o Privado também é Político" (BANDEIRA e MELO, 2010, p. 25). Sendo assim, estando no meio do autoritarismo e da opressão dos regimes militares e de falsas democracias, surge a segunda onda do feminismo na América Latina (COSTA, 2005).

Para Gregori (2017), foi nesse momento político dicotômico, que o feminismo passou a entender a economia e o capitalismo como sendo responsáveis pelas suas opressões. $\mathrm{O}$ movimento feminista brasileiro dos anos 70 , pode ser descrito como um vasto e diverso movimento que luta contra as diversas formas de opressão vivenciada pelas mulheres na sociedade com as lutas pela redemocratização (COSTA, 2005).

Em meados de 1970, o movimento feminista foi marcado pela diversificação em suas pautas, sendo distribuído pelo Brasil e mostrando novas bandeiras, como a dos direitos reprodutivos, do combate à violência contra a mulher e a sexualidade e com isso ganhando mais espaço nas mídias (COSTA, 2005; BANDEIRA e MELO, 2010).

Na década de 80, o movimento social feminista continuou sendo ampliado pela luta do retorno da democracia do país e com a união dos movimentos que declaravam seus direitos específicos dentro da luta geral, sendo, as mulheres lésbicas, pessoas negras e homossexuais (COSTA, 2005; BANDEIRA e MELO, 2010).

Uma grande parte dos grupos feministas até a década de 80 , não se institucionalizavam, eles existiam, tinham práticas, mas não tinham uma institucionalização. O feminismo entrou dentro do âmbito institucional do Estado com a Constituição Federal, e ainda assim gerava dúvidas e receios dentro do movimento, pois era dar confiança para aquele que sempre oprimiu e negou os direitos das mulheres (GREGORI, 2017).

As mulheres participaram ativamente para obter os resultados de políticas sociais que gerassem igualdade de gênero, com esse esforço foi conquistado a "Carta das Mulheres Brasileiras aos Constituintes", onde contém suas reivindicações (PITANGUY, BARSTED e MIRANDA, 2006). Costa acrescenta:

O movimento feminista conseguiu aprovar em torno de $80 \%$ de suas demandas, se constituindo no setor organizado da sociedade civil que mais vitórias conquistou. A novidade desse processo foi a atuação conjunta da chamada "bancada feminina". Atuando como um verdadeiro "bloco de gênero", as deputadas constituintes, independentemente de sua filiação partidária e dos seus distintos matizes políticos, superando suas divergências ideológicas, apresentaram, em bloco, a maioria das propostas, de forma suprapartidária, garantindo assim a aprovação das demandas do movimento (COSTA, 2005, p. 18).

De acordo com Costa (2005), no ano de 2000 deu início a terceira onda do feminismo. Todos os exercícios políticos e organizativos estiveram direcionados para a luta por políticas públicas, aumento de ações afirmativas, aprimoramento da legislação de proteção à mulher e a análise e monitoramento e colocação dessas políticas e acordos postos no campo 
internacional pelos governos locais, tendo articulação e interlocução com o estado. Através dessas lutas foi possível a aprovação da Lei Maria da Penha (BRASIL, 2006) e da Lei 13.104/2015, nomeada Lei do Feminicídio, modificando o Código Penal e englobando o homicídio de mulheres como circunstância qualificadora do crime, tendo penas mais severas, abrangido tais atos no rol de crimes hediondos (BRASIL, 2015b).

\section{Do movimento político a mudanças na educação}

Com esse desenrolar, o ativismo político da mulher ia por fora de uma política institucionalizada, com intenção de induzir as políticas públicas para além do âmbito convencional e institucional (BRABO, 2008). No Brasil as mulheres contrariavam as decisões de poder, com intenção da criação de um novo espaço público, onde elas fossem inseridas. As mesmas questionavam sobre as omissões dos sindicatos, das associações de classe, da discriminação difundida pela imprensa e ensino, para através dessas indagações gerar alterações dentro da estrutura sindical, da organização político-partidária e das leis que regem os direitos civis. Através dessas causas foi criado os Conselhos da Condição Feminina e das Delegacias de Defesa da Mulher (BLAY, 2002).

Essas conquistas citadas acima, foram de extrema importância, pois a partir delas escolas públicas paulistas, tiveram transformações que tinham por intenção sua democratização. Respondendo à proposta do Conselho Nacional dos Direitos da Mulher, a Secretaria Estadual de Educação, com a Assessoria Técnica de Planejamento e Controle Educacional (ATPCE), realizaram um vasto diálogo sobre o papel da mulher na sociedade com as escolas públicas da rede estadual de ensino. Porém essa prática não foi levada adiante, pelo receio governamental dessa democratização (BRABO, 2005).

De acordo com Tânia Brabo (2008), a ideia sobre uma escola democrática segue em pauta, tendo como diferença que em 1980, estava direcionada à gestão democrática e à formação para a cidadania, já em 1990, esteve ligada a associação à reformulação e modernização dos sistemas administrativos, a colocação de programas de avaliação, compra de material didático, capacitação de professores.

Segundo Cláudia Viana e Sandra Unbehaum (2004), uma das conquistas do movimento feminista foi que, nos anos de 1990, no plano nacional, gênero se encontra presente nos Parâmetros Curriculares Nacionais do Ensino Fundamental. Já em 2007, foi apresentado o Plano Nacional de Educação em Direitos Humanos, o que gerou grande acréscimo para o debate sobre igualdade de direitos de mulheres e homens, nas escolas e sociedade.

Essas iniciativas para a cidadania e educação em direitos humanos, existe desde 1990, como exemplo o programa de formação de professores em direitos humanos, quando houve a gestão de Paulo Freire na Secretaria de Educação da cidade de São Paulo. Ainda 
em 1990 foi oferecido o Programa Nacional de Direitos Humanos, o Programa Estadual de Direitos Humanos e em Marília (SP), o Plano Municipal de Direitos Humanos, que tinha por intenção a implementação da educação em direitos humanos, nas escolas de todos os níveis e também fora da escola (BRABO, 2008).

Mesmo tendo uma lentificação nos seus avanços, não dá para negar toda a história e luta das mulheres nas conquistas dos seus direitos. Tudo o que foi dito mostra uma enorme batalha que existiu e que ainda é enfrentada, para adoção de uma perspectiva igualitária de gênero na sociedade.

\section{Metodologia}

A metodologia deste trabalho fundamenta-se na seleção de dissertações de mestrado e teses de doutorado que foram levantadas numa busca de natureza bibliográfica e abordagem quanti-quali através do banco da Biblioteca Digital Brasileira de Teses e Dissertações (BDTD), que foi escolhido por acreditarmos que a plataforma(figura 1) contenha pesquisas sólidas e que tem um papel importante em proporcionar uma maior acessibilidade da produção científica nacional para a sociedade em geral, ponto importante e necessário no momento atual.

A plataforma de busca tem seu lançamento final no ano de 2002, tendo passado ao longo dos anos por diversas atualizações e como a própria plataforma afirma, o BDTD se consolida como uma das maiores iniciativas, do mundo, para a disseminação e visibilidade de teses e dissertações.

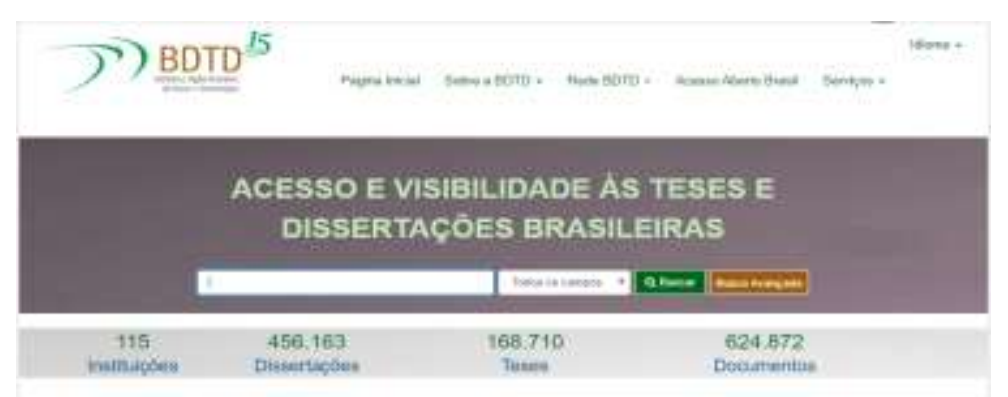

Figura 1 - Site do BDTD

Fonte: < http://bdtd.ibict.br/vufind/>

Dessa forma, o método utilizado para a coleta dos dados deu-se da seguinte forma: inicialmente pelo acesso ao BDTD, busca avançada, com a inclusão das palavras chaves feminismo; Ensino Fundamental; Gênero e (como vemos na figura 2). Neste primeiro filtro buscamos coletar especialmente através da leitura dos títulos e resumos, encontrar teses e dissertações que atendessem nossos objetivos.

Um segundo filtro também foi utilizado pela inserção das palavras chaves feminismo, educação e gênero e os anos de defesa entre 2003 a 2014, para que obtivéssemos um aparato geral de como está sendo feita o trabalho dessa temática na educação geral. Após a 
busca avançada deste segundo filtro, também foram selecionados àqueles eu atendiam ao nosso objetivo.

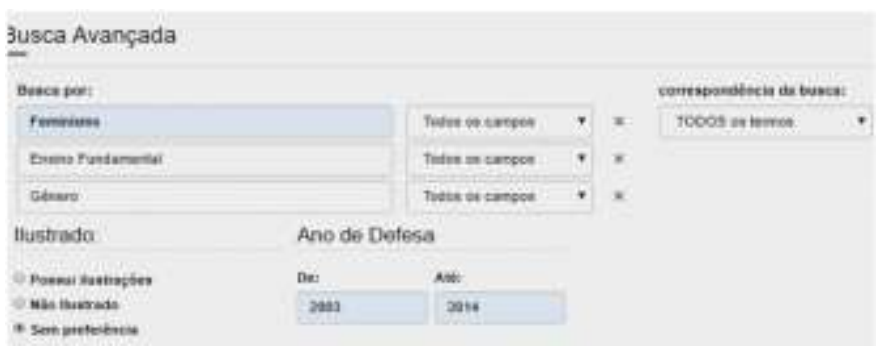

Figura 2 -

Fonte: < http://bdtd.ibict.br/vufind/Search/Advanced>

Outro objetivo a ser alcançado foi identificar as produções acadêmicas por região do país, quanto a quantidade e especificidade. Dessa forma todas as pesquisas foram agrupadas segundo as cinco regiões do país. Este percurso utilizado nos possibilitou nos aproximarmos da diversidade de produções acadêmicas segundo as regiões do país, como também observamos a disparidade de produções entre as mesmas regiões.

\section{Resultados e Discussão}

Após a busca no BDTD, utilizando o primeiro filtro, com os descritores: feminismo, ensino fundamental e gênero, no período de 2003 a 2014, foram identificadas 17 pesquisas acadêmicas entre teses e dissertações (como vemos na tabela 1). Das quais, 7 foram na região Sul, 4 na região Sudeste, 0 na região Norte, 5 na região Nordeste e 1 na região CentroOeste (como vemos na tabela 1). Destes, 5 foram aprovados para análise e outros 12 não se adequavam com o tenta da pesquisa e por esse motivo foram aceitos para análise.

Tabela 1 - Resultado dos trabalhos encontrados pelo 10 filtro 10 Filtro (Feminismo, Ens. Fundamental; Gênero)

\begin{tabular}{cccccc}
\hline $\begin{array}{c}\text { Região } \\
\text { Do } \\
\text { Brasil }\end{array}$ & $\begin{array}{c}\text { TOTAL } \\
\text { NA } \\
\text { REGIÃO }\end{array}$ & $\begin{array}{c}\text { Dissertações } \\
\text { aceitas }\end{array}$ & $\begin{array}{c}\text { Teses } \\
\text { aceitas }\end{array}$ & $\begin{array}{c}\text { TOTAL } \\
\text { ACEITO NA } \\
\text { REGIÃO }\end{array}$ & $\begin{array}{c}\text { TOTAL NÃO } \\
\text { ACEITO NA } \\
\text { REGIÃO }\end{array}$ \\
\hline Centro-Oeste & 1 & 1 & 0 & 1 & 0 \\
\hline Nordeste & 5 & 1 & 0 & 1 & 4 \\
\hline Norte & 0 & 0 & 0 & 0 & 0 \\
\hline Sudeste & 4 & 1 & 1 & 2 & 6 \\
\hline Sul & 7 & 1 & 0 & 1 & 12 \\
\hline $\begin{array}{c}\text { Todas as } \\
\text { regiões }\end{array}$ & 17 & 4 & 1 & 5 & \\
\hline
\end{tabular}

Fontes: Os autores

Ao fazemos a segunda busca com os descritores: feminismo, educação e gênero, entre o mesmo período, foi constatado 133 pesquisas acadêmicas, porém, 126 (como vemos 
na tabela 2) que foram descartados em sua maioria abordavam a temática no gênero no âmbito da graduação. Sendo, 49 da região Sul do Brasil, 34 da região Sudeste, 0 da região Norte, 36 da região Nordeste e 14 da região Centro-Oeste (como vemos na tabela 2). Desse total apenas 7 foram aceitas, dos quais 4 já tinham sidos selecionados no primeiro filtro (como vemos na tabela 4$)$.

Tabela 2 - Resultado dos trabalhos encontrados pelo $1^{\circ}$ filtro

\begin{tabular}{cccccc}
\hline \multicolumn{7}{c}{$2^{-0}$ Filtro (Feminismo; Educação; Gênero) } \\
$\begin{array}{c}\text { Região } \\
\text { Brasil }\end{array}$ & $\begin{array}{c}\text { TOTAL } \\
\text { NA } \\
\text { REGIÃO }\end{array}$ & $\begin{array}{c}\text { Dissertações } \\
\text { aceitas }\end{array}$ & $\begin{array}{c}\text { Teses } \\
\text { aceitas }\end{array}$ & $\begin{array}{c}\text { TOTAL } \\
\text { ACEITO NA } \\
\text { REGIÃO }\end{array}$ & $\begin{array}{c}\text { TOTAL NÃO } \\
\text { ACEITO NA } \\
\text { REGIÃO }\end{array}$ \\
\hline Centro-Oeste & 14 & 1 & 0 & 1 & 13 \\
\hline Nordeste & 36 & 1 & 0 & 1 & 35 \\
\hline Norte & 0 & 0 & 0 & 0 & 0 \\
\hline Sudeste & 34 & 1 & 1 & 2 & 32 \\
\hline Sul & 49 & 2 & 1 & 3 & 126 \\
\hline $\begin{array}{c}\text { Todas as } \\
\text { regiões }\end{array}$ & 133 & 5 & 2 & 7 & \\
\hline
\end{tabular}

Fontes: Os autores

No total, considerando os trabalhos que se enquadravam partir das duas buscas, sem repetições e nos objetivos desta pesquisa, resultaram 8, sendo 6 dissertações e 2 teses (como vemos na tabela 5). Dentre esses 8 trabalhos, aproximadamente, $25 \%$ foram defendidos no ano de 2007, sendo o restante apresentados após o ano de 2010; contabilizando: 2 em 2007, 1 em 2010, 01 em 2012, 2 em 2013 e, por fim, 02 em 2014 (como podemos ver na tabela 03).

Tabela 3 - Resultado dos trabalhos enquadrados na pesquisa por ano

\begin{tabular}{|c|c|c|c|c|c|c|c|c|c|c|c|c|}
\hline ANO & \multicolumn{2}{|c|}{$\begin{array}{l}\text { CENTRO- } \\
\text { OESTE }\end{array}$} & \multicolumn{2}{|c|}{ NORDESTE } & \multicolumn{2}{|c|}{ NORTE } & \multicolumn{2}{|c|}{ SUDESTE } & \multicolumn{2}{|c|}{ SUL } & \multicolumn{2}{|c|}{$\begin{array}{l}\text { TODAS AS } \\
\text { REGIÕES }\end{array}$} \\
\hline $\begin{array}{l}\text { Tese/dis- } \\
\text { sertação }\end{array}$ & $\mathrm{D}$ & $\mathrm{T}$ & D & $\mathrm{T}$ & $\mathrm{D}$ & $\mathrm{T}$ & $\mathrm{D}$ & $\mathrm{T}$ & $\mathrm{D}$ & $\mathrm{T}$ & $\mathrm{D}$ & $\mathrm{T}$ \\
\hline 2003 & & & & & & & & & & & 0 & 0 \\
\hline 2004 & & & & & & & & & & & 0 & 0 \\
\hline 2005 & & & & & & & & & & & 0 & 0 \\
\hline 2006 & & & & & & & & & & & 0 & 0 \\
\hline 2007 & & & & & & & & 1 & 1 & & 1 & 1 \\
\hline 2008 & & & & & & & & & & & 0 & 0 \\
\hline 2009 & & & & & & & & & & & 0 & 0 \\
\hline 2010 & & & & & & & & & 1 & & 1 & 0 \\
\hline 2011 & & & & & & & & & & & 0 & 0 \\
\hline 2012 & & & & & & & 1 & & & & 1 & 0 \\
\hline 2013 & 1 & & & & & & & & & 1 & 1 & 1 \\
\hline 2014 & & & 2 & & & & & & & & 2 & 0 \\
\hline TOTAL & 1 & 0 & 2 & 0 & 0 & 0 & 1 & 1 & 2 & 1 & 6 & 2 \\
\hline
\end{tabular}

Fontes: Os autores 
Tabela 4 - Trabalhos repetidos no 20 filtro em relação ao $1 \%$ filtro

\begin{tabular}{cccc}
\hline Regiões & Dissertações & Teses & TOTAL \\
\hline Centro Oeste & 1 & 0 & 1 \\
\hline Norte & 0 & 0 & 0 \\
\hline Nordeste & 0 & 0 & 0 \\
\hline Sudeste & 1 & 1 & 2 \\
\hline Sul & 1 & 0 & 1 \\
\hline Todas as regiões & 3 & 1 & 4 \\
\hline
\end{tabular}

Fontes: Os autores

Tabela 5 - Trabalhos enquadrados na pesquisa DISSERTAÇÕES

\begin{tabular}{|c|c|c|c|}
\hline Título & Autora(or) & Ano & $\begin{array}{l}\text { Instituição/ } \\
\text { Região }\end{array}$ \\
\hline $\begin{array}{c}\text { Distintos destinos?: a separação entre meninos e } \\
\text { meninas na educação física escolar na perspectiva } \\
\text { de gênero. }\end{array}$ & $\begin{array}{l}\text { Priscila Gomes } \\
\text { Dornelles }\end{array}$ & 2007 & $\begin{array}{l}\text { UFRGS } \\
\text { SUL }\end{array}$ \\
\hline $\begin{array}{l}\text { Anos Iniciais da Escolarização e Relações de } \\
\text { Gênero: representações de docentes sobre gênero. }\end{array}$ & Diana Lusa & 2010 & $\begin{array}{l}\text { UFPEL } \\
\text { SUL }\end{array}$ \\
\hline $\begin{array}{c}\text { A construção do gênero nas Propostas Curriculares } \\
\text { para o último ano da Educação Infantil e primeiro ano } \\
\text { do Ensino Fundamental elaboradas pelo Município } \\
\text { de Marilia/SP. }\end{array}$ & $\begin{array}{l}\text { Elissandra } \\
\text { Medeiros } \\
\text { DallEvedove }\end{array}$ & 2012 & $\begin{array}{l}\text { UNESP } \\
\text { SUDESTE }\end{array}$ \\
\hline $\begin{array}{l}\text { A aula de matemática: a didática do feminino e do } \\
\text { masculino }\end{array}$ & $\begin{array}{l}\text { OtávioHenrique } \\
\text { Braz de Oliveira }\end{array}$ & 2013 & $\begin{array}{l}\text { UnB } \\
\text { CENTRO- } \\
\text { OESTE }\end{array}$ \\
\hline $\begin{array}{c}\text { Leitura e relações de gênero: As discursividades } \\
\text { dos(as) educadores(as) nas medicações de práticas } \\
\text { leitoras. }\end{array}$ & $\begin{array}{l}\text { Gilva } \\
\text { Vasconcelos da } \\
\text { Silva Matos }\end{array}$ & 2014 & $\begin{array}{c}\text { UFPB } \\
\text { NORDESTE }\end{array}$ \\
\hline $\begin{array}{c}\text { Gênero/sexo/sexualidade: Representações e } \\
\text { práticas elaboradas por professoras(es) da educação } \\
\text { infantil na Rede Municipal de Ensino em Salvador. }\end{array}$ & $\begin{array}{c}\text { Amanaiara } \\
\text { Conceição de } \\
\text { Santana Miranda }\end{array}$ & 2014 & $\begin{array}{c}\text { UFBA } \\
\text { NORDESTE }\end{array}$ \\
\hline \multicolumn{4}{|l|}{ TESES } \\
\hline $\begin{array}{l}\text { Relações de gênero em livros didáticos de língua } \\
\text { portuguesa: permanências e mudanças. }\end{array}$ & $\begin{array}{l}\text { Neide Cardoso } \\
\text { de Moura }\end{array}$ & 2007 & $\begin{array}{l}\text { PUC-SP } \\
\text { SUDESTE }\end{array}$ \\
\hline $\begin{array}{l}\text { A (hetero)normalização dos corpos em práticas } \\
\text { pedagógicas da educação física escolar }\end{array}$ & $\begin{array}{l}\text { Priscila Gomes } \\
\text { Dornelles }\end{array}$ & 2013 & $\begin{array}{l}\text { UFRGS } \\
\text { SUL }\end{array}$ \\
\hline
\end{tabular}

Fontes: Os autores 
Entre as pesquisas analisadas, uma das temáticas mais abordadas foi a da questão do gênero na educação física. Donellas (2007), em sua dissertação, discute sobre a separação entre meninas e meninos durantes as aulas de educação física e o quanto isso reforça os estereótipos, reafirmando erroneamente que as meninas são fisicamente inferiores em comparação com os meninos. Essa forma de separação nas aulas revela uma forma de assimilação binária por parte das(os) professoras(es), produzindo assim, uma formação também estritamente biológica, não favorecendo um ambiente de quebra de padrões e estereótipos para as meninas e os meninos.

Já em sua Tese de Doutorado, Dornelles (2013) argumenta que impactos que essa separação dos corpos também provocam uma maneira fixa de se enxergar a sexualidade, gerando uma reprodução que o diferente não é 'normal'. Essa maneira de regulação dos corpos e das sexualidades ainda são práticas comuns em salas de aulas que continuam enxergando os sujeitos como binários e heteronormativos.

Além disso, essas práticas pedagógicas centram-se no trato com a saúde sexual e reprodutiva de forma articulada ao silenciamento das formas de viver a sexualidade distintas da heterossexualidade e à invisibilização das hierarquias sociais existentes nas relações entre homens e mulheres, as quais implicam diretamente o gerenciamento e as negociações do 'sexo seguro' nas relações heterossexuais (DORNELLES, 2013, p.165).

Outro tema citado é a perspectiva literária, Motos (2014) em sua Dissertação de Mestrado, observou a falta de matérias ligados a discussão de gênero na escola onde executou sua pesquisa, o que dificultava o debate de tais assuntos na esfera escolar. Constatou a falta de preparo e de interesse das(os) professoras(es) para tratar desses assuntos. Em sua análise Motos (2014) relata que os próprios alunos trazem consigo dilemas acerca de questão da sexualidade, da identidade, da violência de gênero e doméstica, porém não são realizadas ações de enfrentamento naquele espaço.

Também ao analisar os livros didáticos, Moura (2007), constatou o pouco de representatividade de mulheres nos livros didáticos, como também a forma erronia que são mostradas, como figuras inferiores aos homens, sendo pintadas em situações que a sociedade patriarcal construiu para as mulheres. Ela notou também que na maioria dos livros didáticos analisados tinham como mulheres autoras ou responsáveis pela produção técnica dos livros, e ainda assim esses discursos são repetidos. Foi percebido que os livros que tinham mulheres na capa, como protagonistas tender a serem considerados como produtos voltado para o público feminino.

Em sua Dissertação de Mestrado Miranda (2014), observou a maneira que os professores introduziam assuntos de gênero em turmas do ensino infantil. Com isso, compreende que apesar de que a inclusão dessas temáticas deve ser inserida de acordo com os Parâmetros Curriculares Nacionais (PCN's), na pratica isso não ocorre. Miranda aponta 
um dos motivos que isso acontece é o receio que os professores têm sobre como os pais seriam receptivos com a introdução de tais assuntos. Ela averiguou, por meio de falas dos docentes, uma pratica pedagógica heteronormativa que fortificam estereótipos de gênero.

Lusa (2010) em sua Dissertação de Mestrado, a partir de observações e entrevistas com professoras(res), buscou entender se existiam diferenças pedagógicas em relação com o gênero dos docentes e como isso refletia na dinâmica com os alunos. O resultado é estonteante, quando a própria autora afirma: "São professoras e professor que têm presente as discussões de gênero e talvez por isso pensem mais e acabem fazendo as crianças pensarem mais sobre o "ser menina" e o "ser menino" como algo que se vai construindo " (LUSA, 2010,p.89).

Com base em pesquisas bibliográfica e documental, Evedove (2012), investigou políticas curriculares para o último ano da Educação Infantil e primeiro ano do Ensino Fundamental. Dessa forma, concluiu que os assuntos recomendados pelos Parâmetros Curriculares Nacionais (PCNs), Referencia Curricular Nacional para a Educação Infantil (RCNEI), sobre a temática de gênero, não é por sua vez incorporado nos currículos das escolas analisadas. Sinalizou o desinteresse e receio por parte do corpo acadêmico de aplicar os temas transversais na sala de aula, e discursos extremamente sexistas vindos de alguns profissionais do ensino.

Sustentamos que as experiências educacionais e sociais podem levar meninos e meninas a apresentarem diferentes atitudes afetivas diante da disciplina da matemática derivadas das crenças e valores construídos acerca de seu papel dentro dessa área do conhecimento (OLIVEIRA, 2013, p.41).

Oliveira (2013) em sua dissertação, teve o intuito de analisar a forma que as práticas acadêmicas referentes a disciplina de matemática eram feitas em relação aos aspectos relacionados ao gênero. Foi identificado que o problema principal era a maneira que que a mediação era realizada pelos professores. O ensino estava sendo baseado em interações empobrecidas, ameaças e busca excessiva por controle e padronização das respostas dos alunos e alunas, entre outros resultados; o ensino da matemática era realizado de forma inadequada para estudantes de ambos gêneros.

Por fim, é observado, baseando-se nas análises das produções acadêmicas, de que as práticas dos docentes em sala de aula ainda contêm bases de ensinos binárias, com pouca representatividade em livros e que não produz nos jovens uma quebra de padrões sociais, seja de gênero ou de sexualidade, mas que façam as meninas e os meninos desacostumem ao modelo da feminilidade e da masculinidade, quebrando um sistema de sexo/gênero opressor e excludente daqueles que não seguem a norma. Também foi observado que essas bases de ensinos vão além do material físico - livro, apostila -, mas que é algo trazido pela filosofia pessoal do docente, nos fazendo pensar que para uma abordagem eficaz em sala de aula sobre a temática de gênero, talvez seja preciso fazer o mesmo nas graduações dos 
docentes, para que se tornem professoras e professores que não reproduzam aos alunos discursos estereotipados.

\section{CONSIDERAÇÕES FINAIS}

Mesmo com a inserção dos temas transversais (classe, gênero e raça), nos documentos oficiais do MEC, os Parâmetros Curriculares Nacionais (PCN'S), observamos um limitado número de produções acadêmicas, durante o período estudado sobre as práticas docentes referente a igualdade de gênero no ensino fundamental. Uma das explicações baseia-se numa formação sem que se trabalhe tais temáticas, classe, gênero e raça, orientação religiosa por parte do corpo docente, receio por parte dos(as) professores(as) de serem acusados de impulsionar a sexualidade nas meninas e a homossexualidade nos meninos. No entanto, se faz necessário pensar o processo pedagógico como um meio para a construção de uma sociedade mais igualitária e neste sentido o feminismo pode ser pedagógico e através de ações para além da militância nas ruas, nas academias, nas bancadas das assembleias. Mas no cotidiano, no fazer, no ser e não se ver nem melhor nem pior que outros(as).

\section{REFERÊNCIAS}

BANDEIRA, Lourdes; MELO, Hildete Pereira. Tempos e Memórias do Feminismo no Brasil. Brasília: Secretaria de Políticas para as Mulheres, 2010.

BARSTED, Leila Linhares; MIRANDA, Dayse; PITANGUY, Jacqueline. Um instrumento de conhecimento e de atuação política. In: BARSTED, Leila Linhares; MIRANDA, Dayse; PITANGUY, Jacqueline. (orgs.). O Progresso das Mulheres no Brasil. São Paulo: UNIFEM, 2006.

BLAY, E. A., Género na Universidade», Educação em Revista, Universidade Estadual Paulista, Faculdade de Filosofia e Ciências, n.3, Marília, UNESP-Marília-Publicações, 2002, pp. 73-78.

BRABO, Tânia Suely Antonelli Marcelino. A cidadania da mulher professora, São Paulo, Editora ĺcone, 2005.

BRABO, Tânia Suely Antonelli Marcelino. Educação e democracia: O papel do movimento feminista para a igualdade de gênero na escola. Ex aequo, Vila Franca de Xira, n. 17, p. 155-165, 2008.

BRASIL. Presidência da República. Secretaria de Políticas Públicas para as Mulheres. Lei no 11.340 de 7 de agosto de 2006. Lei Maria da Penha. Brasília: Secretaria de Políticas Públicas para as Mulheres, 2006

BRASIL. Presidência da República. Lei no 13.104 de 9 de março de 2015. 
COSTA, Ana Alice Alcantara. O Movimento Feminista no Brasil: dinâmicas de uma intervenção política. Gênero, Niterói, v.5, n.2,p.9-35, 2005.

COSTA, Ana Alice Alcantara; SARDENBERG, Cecilia Maria. O feminismo no Brasil: uma (breve) retrospectiva. In: COSTA, Ana Alice Alcantara; SARDENBERG, Cecilia Maria (orgs.). O feminismo no Brasil: reflexões teóricas e perspectivas. Salvador: UFBA / Núcleo de Estudos Interdisciplinares sobre a Mulher, 2008.

DALLEVEDOVE, Elissandra Medeiros. A construção de gênero nas propostas curriculares para o último ano da educação infantil e primeiro ano do ensino fundamental elaborado pelo município de Marilia /SP. 2012. 197 f. Dissertação (Mestrado)

- Curso de Pedagogia, Universidade Estadual Paulista, Marilia, 2012.

DORNELLES, Priscila Gomes. Distintos destinos? A separação entre meninos e meninas na educação física escolar na perspectiva de gênero. 2007. 156 f. Dissertação (Mestrado)

- Curso de Pedagogia, Universidade Federal do Rio Grande do Sul, Porto Alegre, 2007.

DORNELLES, Priscila Gomes. A (hetero)normatização dos corpos em práticas pedagógicas da educação física escolar. 2013. 192 f. Tese (Doutorado) - Curso de Pedagogia, Universidade Federal do Rio Grande do Sul, Porto Alegre, 2013.

GREGORI, Juciane de. Feminismos e resistência: trajetória histórica da luta política paraconquista de direitos. Caderno Espaço Feminino - Uberlândia-MG - v. 30, n. 2 Jul./Dez. 2017

LUSA, Diana. Anos iniciais da escolarização e relações de gênero: representações de docentes sobre gênero. 2010. 100 f. Dissertação (Mestrado) - Curso de Pedagogia, Universidade Federal de Pelotas, Pelotas, 2010.

MATOS, Gilva Vasconcelos da Silva. Leituras e relações de gênero: As discursividades dos(as) educadores(as) nas mediações de práticas leitorasS.2014. 152 f. Dissertação (Mestrado) - Curso de Pedagogia, Universidade Federal da Paraĺba, João Pessoa, 2014.

MCKINNON, Catherine, Femininism, Marxism, Method, and State: An Agenda for Theory, Signs (1982) 7:51 5, 541.

MIRANDA, Amanaiara ConceiÇÃo de Santana. Gênero /sexo/sexualidade: Representações e práticas elaboradas por professoras/es da educação infantil na Rede Municipal de Ensino em Salvador. 2014. 166 f. Dissertação (Mestrado) - Curso de Pedagogia, Universidade Federal da Bahia, Salvador, 2014.

MOURA, Neide Cardoso de. Relações de gênero em livros didáticos de língua Portuguesa: Permanências e mudanças. 2007. 245 f. Tese (Doutorado) - Curso de Psicologia, Pontif́́cia Universidade CatÓlica de SÃo Paulo Puc-sp, São Paulo, 2007.

O'BRIEN, Mary, The Politics of Reproduction (Londres: Routledge and Kegan Paul, 1981), pp.8. 15, 46 . 
OLIVEIRA, Otávio Henrique Braz de. A AULA DE MATEMÁtICA: A DIDÁTICA DO FEMININO E DO MASCULINO. 2013. 299 f. Dissertação (Mestrado) - Curso de Psicologia, Universidade de Brasília, Brasília, 2013.

PATERNOTTE, David.; KUHAR, Roman. “Ideologia de gênero” em movimento. Psicologia Política, v.18, n.43, p. 503-523. 2018.

RABAY, Gloria. Freire; CARVALHO, Maria Eulina Pessoa. Participação da mulher no parlamento brasileiro e paraibano. Democracia, Direitos Humanos e Gênero. Org \& Demo, Marília, v.12, n.1, p.81-94, jan./jun., 2011.

RUBIN, Gayle. O tráfico de mulheres. Notas sobre a 'Economia Política' do sexo. Tradução de Christine Rufino Dabat. Recife: SOS Corpo, 1993.

SCOTT, Joan. Gênero: uma categoria útil de análise histórica. Educação \& Realidade, ., v. 20, n. 2, p. 71-79, 1990.

SILVA, Carmen; CAMURÇA, Silvia. Feminismo e movimento de mulheres. Recife: SOS Corpo - Instituto Feminista para a Democracia, 2010.

VIANNA, Claudia Pereira e UNBEHAUM, Sandra (2004), «O género nas políticas públicas de educação no Brasil: 1988-2002», Cadernos de Pesquisa, v. 34, n. 121, pp. 77-104, jan./abr. 